\title{
STATE POLICY IN CONVERGING TECHNOLOGIES: INTERNATIONAL AND RUSSIAN EXPERIENCE IN THE GROWTH STRATEGIES DEVELOPMENT ${ }^{1}$
}

\author{
Elena A. Petrova \\ Volgograd State University, Volgograd, Russian Federation \\ Elena A. Fokina \\ Volgograd State University, Volgograd, Russian Federation
}

\begin{abstract}
The article presents a systematization of distinctions in the converging technologies state policy implemented by foreign countries. NBIC convergence represents a source of a new direction in economic growth, as well as new regional development risks, which require the elaboration of appropriate government policy instruments at all its levels. The authors conclude that effective regional or national innovation policy measures can act as triggers that result in enterprises and scientific organizations entering into a converging technological innovation process, which allow them to take advantage of new emerging markets and industry conditions. In this process, regional or national authorities can play an important role in improving the basic conditions for companies and research institutions in their search for possible application areas, as well as giving them an access to information about modern methods assessing the opportunities and risks associated with converging technologies. The article analyzes the problems and restrictions that enterprises and organizations face on the way to the implementation of NBIC technologies (for example, the lack of specific information about new market opportunities for implementing converging technologies, search and association with new partners outside the sectors where companies operate, etc.) The authors propose directions for the regional specific features analysis, which allow elaborating territorial development programs for implementing converging technologies. Statistical analysis of the digital technologies usage in Russia and cross-country comparison by these indicators carried out by the authors allow concluding that the importance of ICT in the national economy is constantly increasing. The ICT role in building internal business and information interaction between companies and partners is becoming especially important for Russian companies. The level of distribution of cloud services in Russian organizations is comparable to the average for the EU countries. In this area Russia is ahead of France, Germany, and Austria. The industries with the best digitalization rates include the financial sector, retail and communications. At the same time, there remains a significant gap between the achieved level of ICT penetration in Russia and the countries that lead in the broadband Internet access availability, presence in the networks, and the use of information systems.

Key words: NBIC technologies, NBIC convergence, convergent technologies, industry 4.0, digital transformation, economic growth.

Citation. Petrova E.A., Fokina E.A. State Policy in Converging Technologies: International and Russian Experience in the Growth Strategies Development. Vestnik Volgogradskogo gosudarstvennogo universiteta. Ekonomika [Journal of Volgograd State University. Economics], 2021, vol. 23, no. 1, pp. 27-39. (in Russian). DOI: https://doi.org/10.15688/ek.jvolsu.2021.1.2
\end{abstract}




\title{
ГОСУДАРСТВЕННАЯ ПОЛИТИКА \\ В ОБЛАСТИ КОНВЕРГЕНТНЫХ ТЕХНОЛОГИЙ: ЗАРУБЕЖНЫЙ И ОТЕЧЕСТВЕННЫЙ ОПЫТ В ФОРМИРОВАНИИ СТРАТЕГИЙ РАЗВИТИЯ ${ }^{1}$
}

\author{
Елена Александровна Петрова \\ Волгоградский государственный университет, г. Волгоград, Российская Федерация \\ Елена Анатольевна Фокина \\ Волгоградский государственный университет, г. Волгоград, Российская Федерация
}

\begin{abstract}
Аннотация. В статье представлена систематизация различий в реализации государственной политики в области конвергентных технологий, осуществляемой зарубежными странами. НБИК-конвергенция выступает в качестве источника как нового направления экономического роста, так и новых рисков регионального развития, что требует разработки соответствующих инструментов государственной политики на всех ее уровнях. Сделан вывод о том, что эффективные меры региональной или национальной инновационной политики способны быть триггерами, в результате которых предприятия и научные организации могут вступать в конвергентный технологический инновационный процесс, позволяющий им использовать преимущества новых развивающихся рынков и условий в отрасли. В этом процессе региональные или национальные власти могут сыграть важную роль в улучшении базовых условий для компаний и исследовательских учреждений в их поиске возможных областей применения, а также доступа к информации, современным методикам оценки возможностей и рисков, связанных с технологической конвергенцией. В статье проведен анализ проблем и барьеров, которые возникают перед предприятиями и организациями на пути внедрения НБИК-технологий (нехватка информации именно о новых рыночных возможностях применения конвергентных технологий, поиск и объединение с новыми партнерами вне секторов, где действуют компании, и др.). Авторами предлагаются направления анализа региональной специфики, которая позволит сформировать программы территориального развития по применению конвергентных технологий. Проведенный анализ статистики применения цифровых технологий в России и межстрановые сравнения по этим показателям позволяют сделать вывод о том, что значение ИКТ в национальной экономике постоянно возрастает. Особенно значимой для российских компаний становится роль ИКТ в выстраивании внутреннего бизнеса и информационном взаимодействии компаний с партнерами. Уровень распространения облачных сервисов в российских организациях сопоставим со средним по странам ЕС, в то же время по этому направлению Россия опережает Францию, Германию, Австрию. В качестве отраслей, в которых достигнуты наибольшие успехи в деле цифровизации, можно назвать финансовый сектор, розничную торговлю и связь. Вместе с тем сохраняется существенный разрыв достигнутого уровня распространения ИКТ в России со странами - лидерами по распространению широкополосного доступа к Интернету, присутствию в Сети, использованию информационных систем.

Ключевые слова: НБИК-технологии, NBICS-конвергенция (NBICS convergence), конвергентные технологии, индустрия 4.0, цифровая трансформация, экономический рост.

Цитирование. Петрова Е. А., Фокина Е. А. Государственная политика в области конвергентных технологий: зарубежный и отечественный опыт в формировании стратегий развития // Вестник Волгоградского государственного университета. Экономика. - 2021. - Т. 23, № 1. - С. 27-39. - DOI: https://doi.org/10.15688/ ek.jvolsu.2021.1.2
\end{abstract}

\section{Введение}

Развитие и широкое применение конвергентных технологий является глобальной тенденцией, императивом для сохранения устой- чивых темпов экономического роста. Ключевые идентифицированные области конвергенции - информационные и компьютерные технологии, нанотехнологии, биотехнологии, а также когнитивные ресурсы в ориентации на 
искусственный интеллект, проникая и взаимодействуя друг с другом, вызывают изменения в глобальной и национальной экономике.

В конце XX - начале XXI в. произошла смена парадигмы общественного производства, что привело к существенному инновационному обновлению производства, смещению роли факторов производства, доминирующему положению в ВВП нематериальных элементов. По экспертным оценкам, рост ВВП будет более чем на $50 \%$ связан с развитием новых технологий и разработок [Что такое цифровая экономика ...].

Процессы конвергенции технологий видоизменяют общественную систему в целом. Определение приоритетов развития конвергентных технологий становится одним из основных элементов государственной стратегии, а также среднесрочных планов развития. Использование НБИК-технологий как новых точек экономического роста требует формирования соответствующих инструментов государственной политики, включая ее структурную, налогово-бюджетную и денежно-кредитную составляющие.

Немаловажное значение приобретает нормативно-правовое обеспечение, которое становится связующим компонентом новой экономической политики и базой научно-технологического развития.

Однако инновационные конвергентные технологии являются также и источниками новых рисков, что требует их учета при формировании технологических траекторий и сбалансированности социально-экономического развития.

Таким образом, НБИК-конвергенция выступает источником как нового направления экономического роста, так и новых рисков регионального развития, что требует разработки соответствующих инструментов государственной политики на всех ее уровнях.

\section{Государственная политика в области} развития конвергентных технологий в РФ и ведущих инновационных странах: проблемы и практические меры реализации

Усиление влияния конвергентных технологий на темпы, качество и устойчивость эко- номического роста придает проблеме выбора инструментов экономической политики особую значимость, вызывая повышенное внимание к ней со стороны отечественных и зарубежных ученых.

В последние десятилетия теоретические модели экономического роста подчеркивали важность распространения и конвергенции технологий [Grossman et al., 1991]. Западные ученые [Rodrik et al., 2002] признают, что «институты имеют значение для экономического развития», при этом межстрановые эмпирические исследования связывают качество макроэкономической политики с более высокими уровнями дохода на душу населения и более высоким экономическим ростом. В исследованиях Ч. Джонса [Jones, 2002] отмечается вклад человеческого капитала в экономический рост. Работа авторов [Acemoglu et al., 2012] отражает различие в экономических структурах, объясняет различные политические институты и скорость технологического прогресса. К. Уорвик [Warwick, 2013] развивает значение государственной политики, направленной на экономическую активность по секторам новых технологий, которая необходима для устойчивого экономического роста.

Российские ученые, изучающие фундаментальные проблемы территориальной организации экономики на базе формирующегося нового технологического уклада, делают акцент на необходимости построения различных видов экосистем [Иншаков, 2007; Клейнер, 2019; Иншакова, 2020].

Теоретические и эмпирические исследования показывают, что причинно-следственная связь НБИК-технологий направлена от человеческого капитала к качеству национальной институциональной среды и через среду к экономическому росту и технической модернизации. Многие исследователи подчеркивают важность новых технологий в повышении темпов роста, а также критичность создания определенных политических предпосылок для достижения нового уровня социально-экономического развития.

Государственная политика регулирования экономических процессов новой цифровой экономики включает в себя как вопросы реформирования информационных правоотношений, так и обусловленное общей глобальной тен- 
денцией формирование институциональной экосистемы и особой политической ситуации.

В Послании Президента Российской Федерации Федеральному Собранию [Послание Президента РФ, 2016] подчеркивается, что для выхода на новый уровень развития экономики, социальных отраслей необходимо сосредоточиться на цифровых сквозных технологиях, которые сегодня определяют облик всех сфер жизни и концентрируют в себе мощный технологический потенциал будущего. Причем успешная реализация государственных программ, направленных на повсеместное использование цифровых технологий, возможна только при условии целостного и системного реформирования экономики в стране. Объективно, что мероприятия в сфере развития цифровой экономики необходимо реализовывать согласованно с совершенствованием информационной защиты, повышением устойчивости всех элементов инфраструктуры, финансовой системы, государственного управления.

К настоящему моменту приняты определенные шаги, направленные на внедрение новых технологий в национальную экономику: «Доктрина информационной безопасности РФ» [Указ Президента РФ, 2016], «Стратегия экономической безопасности Российской Федерации до 2030 г.» [Указ Президента РФ, 2017], «Стратегия развития информационного общества РФ на 2017-2030 гг.» [Указ Президента РФ, 2017]. Однако стоит отметить, что нормативные правовые акты нуждаются в постоянной актуализации и корректировке в связи с частыми изменениями направляемого трансформационного процесса, сфер применения новых технологий, а также степени их значимости для экономического роста в РФ.

В рамках реализации Указа Президента Российской Федерации от 7 мая 2018 г. № 204 «О национальных целях и стратегических задачах развития Российской Федерации на период до 2024 года» Правительством РФ был разработан и утвержден Национальный проект «Цифровая экономика» [Постановление Правительства РФ, 2019], ключевой целью которого является ускоренное внедрение цифровых технологий в экономику и социальную сферу, что создаст условия для высокотехнологичного бизнеса, повысит конкурентоспо- собность страны на глобальном рынке, укрепит национальную безопасность и повысит качество жизни людей. Программа «Цифровая экономика» развивает основные положения Стратегии развития информационного общества и является по настоящему комплексной, ориентированной на преобразования как нецифровых (политика и стратегическое планирование; институты; законодательство; человеческий капитал и др.), так и цифровых факторов (цифровая инфраструктура, включающая широкополосные, беспроводные сети и цифровизацию традиционной физической инфраструктуры; цифровые платформы, конвергентные технологии).

При всем разнообразии подходов к определению регулирующей роли государственных институтов в формировании общей цифровой инфраструктуры, центральное место занимают несколько основных направлений:

1. Выработка стратегии цифрового правительства, дополненной планом действий и инструментами воздействия.

2. Обновление федеральных и региональных целевых программ поддержки конвергентных технологий как основы формируемой цифровой экономки.

3. Реализация политики по поддержке технологического и экономического развития организаций с разработкой общей стратегии, а также содействие использованию данных и новых технологий в коммерческом секторе.

4. Расширение государственной поддержки привлечения частных инвестиций в инновационную сферу, в том числе с использованием механизмов государственно-частного партнерства. В этом контексте особое внимание уделяется использованию нового инструмента научно-технологической политики технологических платформ.

5. Создание гибкой и благоприятной нормативной среды для совместных инвестиций в исследовательские проекты, реализуемые на базе вузов, независимых центров НИОКР, технопарков и отдельных компаний.

6. Распространение новых инструментов вовлечения человеческого капитала в инновационные процессы наряду с центральной политикой стимулирования инноваций.

Эффективная региональная хозяйственная система, а также результативные меры 
региональной или национальной инновационной политики способны быть триггерами, в результате которых предприятия и научные организации могут вступать в конвергентный технологический инновационный процесс, позволяющий им использовать преимущества новых развивающихся рынков и условий в отрасли. Изучение сильных сторон региона новыми способами (то есть через технологическую перспективу) может улучшить инновационную структуру в регионе, и это может привести к внутренним инвестициям и улучшению структуры для местных компаний в целом. Тем не менее технологическая конвергенция не была главным приоритетом в политической повестке дня в зарубежных странах, и еще в меньшей степени в России, несмотря на положительные примеры конвергенции технологий как на исследовательских площадках, так и на рынке (появление новых сегментов, например функциональные продукты питания) и увеличение использования новейших технологий в коммерческих целях.

Такие понятия, как «кластеры» и «инновации», определяют развитие региональной политики в Европе и странах Северной Европы уже более десяти лет. В странах Северной Америки (США и Канада) конвергентный технологический подход также играет центральную роль в региональной политике, лучшим примером которой является Силиконовая долина - одна из новаторских областей кластерного развития, в которой был реализован новый технологический подход, основанный на конвергенции технологий.

В статье «Next Silicon Valley: Riding the Waves of Innovation» [Next Silicon Valley ..., 2001] описан пример такого сближения биоинформационных технологий и применение нанотехнологий в производстве полупроводников и компьютеров. Общая цель использования конвергентного технологического подхода в будущей стратегии Силиконовой долины была описана как «развитие сетей, которые обновляют среду для инноваций и предпринимательства», что, в свою очередь, предполагало более тесное сотрудничество региональных властей с руководством Силиконовой долины.

Пример из Силиконовой долины показывает, что конвергентные технологии являются активным элементом в одном из самых конкурентоспособных регионов мира. Для региональных и национальных программ развития это потребует не только анализа региональной инновационной системы, включая критическую теоретическую оценку сильных сторон территориальной экономики, но и оценки научно-исследовательского потенциала региона.

Как ранее уже было сказано, конвергентные технологии могут быть не только источником инноваций, открывающих новые возможности для экономики, но также способны представлять угрозу для компаний, если они не реагируют на изменения, происходящие в их отрасли, на этапах эволюционной конвергенции. Фактические возможности могут существенно отличаться от одной компании к другой. В этом процессе региональные или национальные власти играют важную роль в улучшении базовых условий для компаний и исследовательских учреждений в их поиске возможных областей применения, а также доступа к информации, современным методикам оценки возможностей и рисков, связанных с технологической конвергенцией.

Для конкретных компаний, которые намерены использовать преимущества конвергентных технологий, стоит проблема внедрения технологической конвергенции как части четкой бизнес-стратегии. В этом случае возможны два варианта: использовать преимущества конвергентных технологий на разных этапах с использованием технологического актива на новом рынке или путем внедрения появляющейся общей технологии в существующие продукты, создавая тем самым возможности в новых отраслях или вводя радикально измененные продукты в текущий рынок. Второй стратегический подход для начинающих компаний заключается в определении дополнительных нишевых областей либо на предварительных стадиях, либо на стадии коммерциализации процесса конвергенции. Однако для такого участия в использовании конвергентных технологий на региональном уровне существует целый класс проблем, в решении которых ключевая роль отводится региональным властям.

Существующие и стимулирующие технологии важны для конвергентного технологи- 
ческого инновационного процесса, и компаниям требуется доступ к открытой информации о существующих технологиях, их возможных сферах применения и коммерциализации. Чтобы стимулировать более широкие знания о коммерческих возможностях, возникающих в результате технологической конвергенции, территориальным органам исполнительной власти, формирующим региональную политику на основе государственно-частного партнерства (ГЧП), целесообразно проводить анализ потенциальных коммерческих приложений параллельно с более широкими мерами информирования потенциальных участников этих процессов. Предприятиям и организациям сложно найти новых партнеров за пределами своих традиционных рыночных секторов. Поиск партнеров особенно воспринимается как сложный, если это касается другой отрасли, сектора или новых областей техники и технологий. В контексте технологической конвергенции инкубаторы и сети играют немаловажную роль.

В этой связи очень интересны результаты исследования «Applying Technology Convergence for Innovation in Nordic region», проведенного Nordic Innovation Centre (NICe) в странах Северной Европы в 2009 г. и посвященного проблемам и барьерам применения НБИК-технологий в инновационных процессах [Applying Technology ..., 2009].

Главный вывод состоял в том, что основные проблемы, с которыми сталкиваются компании, связаны с нехваткой информации об участии в конвергентных инновационных процессах. С одной стороны, компании в основном воспринимали нехватку информации как неспособность определить соответствующие источники информации, а также существенный барьер. С другой стороны, не хватает информации именно о новых рыночных возможностях применения конвергентных технологий. В тех случаях, когда имеются положительные примеры такого использования НБИК-технологий, это было вызвано в большей степени не целенаправленными действиями, а требованиями партнеров или условиями внешней среды.

Другим главным барьером на пути внедрения технологических инноваций является выявление и объединение новых партнеров.
Кроме того, инициативы, касающиеся конвергенции, должны составлять часть комплексной долгосрочной инвестиционной стратегии, а не «одноразовых мероприятий».

В то же время исследование показало, что программы поддержки региональными властями должны быть дифференцированы по типу и масштабам компаний (индивидуальные предприниматели, малые и средние компании и крупные компании). В этом контексте фьючерсные методы, такие как сценарии, предвидения и технологическое дорожное картирование, могут быть методами выявления и изучения стратегических возможностей и ключевых факторов неопределенности относительно поведения рынка и скрытого рыночного спроса на новые или улучшенные продукты и услуги, основанные на технологической конвергенции.

Важной проблемой при формировании региональных политик использования НБИКтехнологий в инновационных процессах остается резкая дифференциация самих регионов по уровню экономического развития. В этой связи необходимо учитывать возможности самого региона (инфраструктурные условия, научный потенциал, наличие высокотехнологичных отраслей в регионе) при формировании региональных стратегий развития. Представляется целесообразным выделить две группы регионов - с низкотехнологичными и высокотехнологичными отраслями.

Конвергентные технологии в основном развиваются за счет применения и объединения уже существующих знаний новыми способами. В высокотехнологичных регионах обычно имеются условия, где производство новых научных исследований и разработок, основанных на знаниях, имеет решающее значение для компаний региона. Как фундаментальные, так и прикладные исследования, а также систематическое развитие продуктов и процессов являются актуальными видами деятельности. Часто эти регионы содержат высокотехнологичные компании, которые тесно сотрудничают с университетами или научными центрами.

В регионах с низкотехнологичными отраслями обычно отсутствуют научные фундаментальные исследования, но могут присутствовать некоторые прикладные исследо- 
вания. Как правило, сильная институциональная инфраструктура подкрепляет уникальные региональные преимущества традиционной отрасли. В этих регионах сильны сети с активными посредническими организациями. Ключевой движущей силой сетевого взаимодействия является потенциал сотрудничества. Таким образом, в региональных отраслях существуют общие проблемы, которые могут быть решены путем применения конвергентных технологий.

Большинство регионов знают о своих региональных конкурентных преимуществах, которые часто представлены в стратегиях регионального развития в виде кластеров или отдельных отраслей промышленности. Однако возможности в рамках новых формирующихся технологий и межсекторального сотрудничества, как правило, не являются частью диагностики отраслей или кластеров.

Одним из главных преимуществ инноваций с помощью конвергентных технологий является то, что участвующие в них компании часто не являются прямыми конкурентами. Следовательно, по сравнению с другими инновационными моделями, такими как открытые инновации, риск потери знаний конкурентами ниже, и инновации могут происходить за пределами ранних стадий научно-исследовательских проектов. Конвергентная технология - это не инновационная модель как таковая, а стратегический подход, который может быть использован в рамках других инновационных моделей.

Конвергентный технологический подход должен быть частью регионального анализа, проводимого при разработке или обновлении региональных стратегий развития. Реализовать такой анализ возможно на региональных технологических форсайт-мероприятиях, например путем детального выявления основных сильных сторон региональных подотраслей и изучения факторов спроса, имеющих отношение к конкретному региону, их промышленным характеристикам и технологическим активам. Отраслевой анализ должен не только высветить сильные стороны местных компаний по сравнению с другими регионами, но и выделить возможные пути применения новых технологий, сотрудничества с другими секторами и преимущества исследовательс- кой базы (например, университетов, сетей и научных парков) в регионе.

Стратегия должна основываться на текущих и будущих технологиях, влияющих на региональные отрасли экономики и научную базу.

Региональные мероприятия по технологическому форсайту могут предоставить региону стратегический метод для выявления внутренней синергии между отраслями и подотраслями по использованию новых технологий (ИКТ, нанотехнологии, биоинформатика).

Предлагаются следующие направления анализа региональной специфики, которые позволят сформировать программы территориального развития по применению конвергентных технологий:

1. Провести анализ сильных сторон в ключевых секторах экономики, в результате которого определить те подотрасли, которые должны быть в центре внимания региональной стратегии конвергентных технологических инноваций. Данный анализ должен выявить сильные стороны как отдельных предприятий и организаций, так и научно-исследовательской сферы региона.

2. Провести типологизацию предприятий и выявить основные промышленные характеристики, включая цепочки создания стоимости, чтобы сформировать управленческие воздействия по каждому типу предприятий.

3. Определить отрасли, подотрасли и технологии, имеющие важное значение в будущем. Цель состоит в том, чтобы найти возможности в других отраслях и информацию о технологиях, которые, вероятно, окажут влияние на перспективную отрасль в будущем.

4. Привлечь руководителей предприятий, организаций, научных центров и экспертов для участия в форсайт-мероприятиях.

5. Определить конвергентные технологии, которые соответствуют выделенным на предыдущем этапе отраслям и подотраслям. В ходе анализа руководители предприятий и эксперты совместно должны выработать конкретные мероприятия по использованию НБИК-технологий, которые должны затем войти в формируемые региональными властями Стратегии и программы развития. 


\section{Зарубежный и российский опыт развития информационного сектора экономики}

За последние десятилетия ранее существующие границы исчезли в таких секторах, как информационный и телекоммуникационный, беспроводная связь и интернет-технологии (ИТ). Следующим этапом конвергенции стали нанотехнологии (НТ), биотехнологии (БТ) и когнитивные ресурсы (КТ), что привело к формированию уникального явления НБИК-технологий. Однако центральное место в этом конгломерате остается за информационными технологиями, которые и определяют их дальнейшее развитие. Именно поэтому необходимо остановиться на измерении уже достигнутых в этом направлении результатов и понять, какова роль НБИК-технологий в экономическом росте.

Традиционно измерение экономического роста связывают с таким показателем, как валовой внутренний продукт (ВВП). По страновым оценкам, годовые темпы прироста ВВП показывают общую тенденцию снижения во всем мире. В развивающихся странах во главе с Индией и Китаем темпы прироста ВВП за период 2015-2019 гг. являются относительно высокими, но, тем не менее, наблюдается тенденция снижения: темпы прироста в Китае сократились с 11,4 \% в 2005 г. до 6,1 \% в 2019 г., в Индии - с 9,3\% до 6,1 \% (см. таблицу). В докризисный период (2005-2008 гг.) российская экономика демонстрировала впечатляющую динамику, после кризиса (20092013 гг.) рост замедлился и в 2016-2019 гг. стал близок к $1 \%$.
Принимаемые правительством меры, в том числе общенациональный план действий, обеспечивающие восстановление занятости и доходов населения, рост экономики и долгосрочные структурные изменения, помогут уменьшить спад ВВП в 2020 г. на 1,0-1,5 процентных пункта. Вместе с тем, несмотря на возникновение новых технологичных секторов, осуществляемые и планируемые действия, рост российской экономики остается низким и неустойчивым и в ближайшие годы не превысит $3 \%$ в год [Постпандемическое восстановление ..., 2020].

В зависимости от используемого определения размер цифровой экономики составляет, по оценкам, от 4,5 до 15,5\% мирового ВВП. Почти 40 \% добавленной стоимости, создаваемой в мировом секторе информационно-коммуникационных технологий, приходится на Соединенные штаты и Китай [Доклад ..., 2019]. В 2018 г. в Китае на цифровую экономику пришлось 38,2 \% от ВВП [Цифровой потенциал ..., 2019], что обусловлено внедрением информационно-коммуникационных технологий в традиционные сектора. Тем не менее ожидается замедление темпов роста экономики Китая по мере приближения к технологическому пределу.

Заметим, что выявленная тенденция замедления роста происходит на фоне внедрения национальных и межгосударственных программ и стратегий цифрового развития. Так, например, Германия, являющаяся главным идеологом концепции «Индустрии 4.0», представляет несколько стратегий (Industrie 4.0, Smart Networking Strategy). Великобритания внедряет Стратегию развития цифровой эко-

Таблииа

Темп прироста ВВП (\% в год) в 2005-2019 гг.

\begin{tabular}{|l|c|c|c|c|c|c|c|c|c|c|c|}
\hline \multicolumn{1}{|c|}{ Страна } & 2019 & 2018 & 2017 & 2016 & 2015 & 2014 & 2013 & 2012 & 2011 & 2010 & 2005 \\
\hline Индия & 6,1 & 6,8 & 7,2 & 8.2 & 8,0 & 7,4 & 6,4 & 5,5 & 6,6 & 10,3 & 9,3 \\
\hline Китай & 6,1 & 6,6 & 6,8 & 6,7 & 6,9 & 7,3 & 7,8 & 7,9 & 9,5 & 10,6 & 11,4 \\
\hline Индонезия & 5,0 & 5,2 & 5,1 & 5,0 & 4,9 & 5,0 & 5,6 & 6,0 & 6,2 & 6,4 & 5,7 \\
\hline США & 2,4 & 2,9 & 2,4 & 1,6 & 2,9 & 2,5 & 1,8 & 2,2 & 1,6 & 2,6 & 3,5 \\
\hline Великобритания & 1,2 & 1,4 & 1,8 & 1,8 & 2,3 & 2,9 & 2,0 & 1,4 & 1,6 & 1,7 & 3,1 \\
\hline Франция & 1,2 & 1,7 & 2,3 & 1,1 & 1,1 & 1,0 & 0,6 & 0,3 & 2,2 & 1,9 & 1,7 \\
\hline Россия & $\mathbf{1 , 1}$ & $\mathbf{2 , 3}$ & $\mathbf{1 , 6}$ & $\mathbf{0 , 3}$ & $\mathbf{- 2 . 3}$ & $\mathbf{0 , 7}$ & $\mathbf{1 , 8}$ & $\mathbf{3 , 7}$ & $\mathbf{5 , 1}$ & $\mathbf{4 , 5}$ & $\mathbf{6 , 4}$ \\
\hline Япония & 0,9 & 0,8 & 1,9 & 0,6 & 1,2 & 0,4 & 2,0 & 1,5 & $-0,1$ & 4,2 & 1,7 \\
\hline Бразилия & 0,9 & 1,1 & 1,1 & $-3,3$ & $-3,6$ & 0,5 & 3,0 & 1,9 & 4,0 & 7,5 & 3,2 \\
\hline Германия & 0,5 & 1,5 & 2,5 & 2,2 & 1,7 & 2,2 & 0,4 & 0,4 & 3,9 & 4,2 & 0,7 \\
\hline
\end{tabular}

Примечание. Составлено авторами по: [Международный валютный фонд]. 
номики (UK Digital Strategy), целью которой является мировое лидерство в построении киберпространства. Франция создает «Альянс индустрии будущего», объединяющий различные организации бизнес-сектора, научной среды и ряд государственных институтов. Япония реализует национальную стратегию ( $\mathrm{New}$ Strategy in Information and Communications Technology), в которой обозначены ключевые направления развития информационно-коммуникационных технологий. В США разработана программа «Электронная экономика» (Digital Economy Agenda). В программе выделены основные направления: бесплатный и открытый Интернет для расширения международной торговли и минимизации барьеров со стороны правительства; доверие и безопасность в Интернете; доступность Интернета, включая обучение пользователей навыкам работы; инновации и новые технологии в цифровой экономике. В Китае принят стратегический план развития, направленный на реиндустриализацию страны. Согласно Стратегии Made in China (MIC 2025), предполагается преодоление разрыва в десяти стратегически важных сферах, включая новые информационнокоммуникационные технологии.

Согласно исследованию «Цифровая Россия: новая реальность», проведенному Digital McKinsey - глобальной экспертной группой, в последние годы в России зафиксировано существенное ускорение развития ИКТ и процессов конвергенции технологий. Интенсивные изменения в секторе ИКТ характеризуются:

1. Нарастанием экономического использования интернет-технологий. Эффективность использования сетевых ресурсов в значительной степени определяет наличие качественного, скоростного доступа к сети Интернет. В 2011-2018 гг. в России наблюдался активный рост числа абонентов мобильного и фиксированного широкополосного доступа к Интернету (ШПД) в расчете на 100 человек населения, что сопоставимо со средними показателями по Европе и превосходит среднемировые показатели. Среднегодовой темп прироста абонентов фиксированного ШПД за 2008-2018 гг. в мире составил 8,7\%, в России $-12,8 \%$, мобильного - 27,1 и $8,7 \%$.

2. Продолжением развития электронной торговли. Электронные продажи наиболее ак- тивно ведутся в Австралии, Ирландии, Швеции (32-48 \% организаций). В России $15 \%$ организаций в 2018 г. продавали товары и услуги по заказам, полученным по Интернету (через вебсайт, экстранет, EDI-сообщения) [Тенденции развития интернета ..., 2020].

3. Формированием облачных сервисов. В последние годы набирают популярность ИТсервисы - хранилища данных в сети Интернет, реализуемые на облачной платформе. Показатель распространения облачных сервисов в российских организациях сопоставим со средним по странам ЕС - $21 \%$. В большей степени, чем в России, облачные сервисы востребованы в Финляндии (57\%), Швеции (48 \%), Россия опережает США (17\%) [Тенденции развития интернета ..., 2020], Францию и Германию (16 \%) [Цифровая экономика ..., 2017].

Как показывает анализ статистики применения цифровых технологий в России и межстрановые сравнения по этим показателям, хотя у нашей страны и имеется некоторое отставание от лидеров, значение ИКТ в национальной экономике постоянно возрастает. Особенно значимой для российских компаний становится роль ИКТ в выстраивании внутреннего бизнеса и информационном взаимодействии компаний с партнерами. Уровень распространения облачных сервисов в российских организациях сопоставим со средним по странам $\mathrm{EC}$, в то же время по этому направлению Россия опережает Францию, Германию, Австрию.

В качестве отраслей, показывающих наибольшие успехи в деле цифровизации, можно назвать финансовый сектор, розничную торговлю и связь. Вместе с тем сохраняется существенный разрыв достигнутого уровня распространения ИКТ в России со странами - лидерами по распространению широкополосного доступа к Интернету, присутствию в Сети, использованию информационных систем.

\section{Заключение}

Страны и регионы Организации экономического сотрудничества и развития (ОЭСР) уже интегрировали конвергентные технологии в свою инновационную политику в качестве стратегического инструмента для улучшения региональных и национальных инновационных 
стратегий и систем. Новые модели появляются в кросс-поле между существующими и внедряемыми технологиями и посредством развертывания междисциплинарных коммерческих и технологических навыков. Хотя конвергентные технологии недостаточно широко интегрированы в региональную инновационную политику Европейского союза, регионы и страны за пределами ЕС все чаще используют конвергентные технологии в качестве стратегического инструмента при разработке политики. Данная задача наиболее остро стоит и перед Российской Федерацией, несмотря на успешную реализацию национальной программы «Цифровая экономика».

Анализ, проведенный авторами, показывает, что для разработки программ внедрения НБИК-технологий потребуется междисциплинарный подход, учитывающий факторы рыночного спроса, что позволит извлечь потенциальные выгоды от использования технологической конвергенции.

Внедрение новой инновационной стратегии на основе конвергентных технологий предполагает наличие в регионах развитого научного сектора (университеты, научные и технопарки, отраслевые исследовательские организации).

Развитие региональной конвергентной технологической платформы в пределах определенных промышленных и технологических преимуществ региона происходит с непосредственным участием научно-исследовательского сектора и поддерживается региональными властями.

Первым шагом по разработке общей стратегии и практических мероприятий внедрения конвергентных технологий в региональную экономику должна стать форсайт-сессия, объединяющая университеты, компании, государственный сектор и эффективно действующие кластеры. Региональная политика в целом должна быть направлена на объединение уже существующих активных кластеров и создание условий для партнерских отношений как внутри региона, так и стремление к созданию партнерских отношений также и с другими регионами.

В целях оценки и повышения качества управленческих воздействий на конвергентные процессы необходимо формирование мо- дели экономики, способствующей созданию условий для развития НБИК-технологий, а также активного участия региональных органов власти в реализации мероприятий в данной сфере, в частности посредством реализации проектов, связанных с выпуском новых видов услуг (продукции) с высокой добавленной стоимостью, и апробирования стратегий.

\section{ПРИМЕЧАНИЕ}

${ }^{1}$ Исследование выполнено при финансовой поддержке РФФИ и Администрации Волгоградской области в рамках научного проекта № 19-410340014 р а «Совершенствование механизмов и инструментов экономического роста регионов РФ в условиях развития конвергентных технологий».

The reported study was funded by Russian Foundation for Basic Research and the government of Volgograd region according to the research project "Improvement of mechanisms and instruments of economic growth in Russian regions in terms of development of convergent technologies", project No. 19-410-340014 p_a.

\section{СПИСОК ЛИТЕРАТУРЫ}

Доклад о цифровой экономике. Создание стоимости и получение выгод: последствия для развивающихся стран, 2019. - Электрон. текстовые дан. - Режим доступа: https://unctad.org/ system/files/official-document/der2019_ overview_ru.pdf. - Загл. с экрана.

Иншаков, О. В. Экономическая генетика и наноэкономика / О. В. Иншаков. - Волгоград : Изд-во ВолГУ, 2007.- $94 \mathrm{c}$.

Иншакова, Е. И. Формирование экосистемы цифровой экономики Российской Федерации: институциональный аспект // Вестник Волгоградского государственного университета. Экономика. - 2020. - Т. 22, № 4. - С. 5-17. DOI: https://doi.org/10.15688/ek.jvolsu.2020.4.1.

Клейнер, Г. Б. Экономика экосистем: шаг в будущее / Г. Б. Клейнер // Экономическое возрождение России. - 2019. - № 1 (59). - С. 40-45.

Международный валютный фонд. - Электрон. текстовые дан. - Режим доступа: https://www.imf. org/en/Publications/WEO/weo-database/2020/ October; https://knoema.com. - Загл. с экрана.

Послание Президента Российской Федерации Федеральному Собранию от 01.12.2016 // Парламентская газета. -2016 . - № 45 (2 дек.).

Постановление Правительства РФ от 02.03.2019 № 234 «О системе управления реализацией 
национальной программы “Цифровая экономика Российской Федерации”» : (в ред. от 21.08.2020). - Электрон. текстовые дан. - Режим доступа. http://www.consultant.ru/ document/cons_doc_LAW_319701/.-Загл. c экрана.

Постпандемическое восстановление Российской экономики и переход к устойчивому социально-экономическому развитию / А. Г. Аганбегян [и др.] // Проблемы прогнозирования. 2020. - № 6. - С. 18-26.

Тенденции развития интернета в России и зарубежных странах: аналитический доклад / Г. И. Абдрахманова [и др.]. - М. : НИУ ВШЭ, 2020. 144 с. - Электрон. текстовые дан. - Режим доступа: https://issek.hse.ru/mirror/pubs/share/ 345060549.pdf. - Загл. с экрана.

Указ Президента РФ от 05.12.2016 № 646 «Об утверждении Доктрины информационной безопасности Российской Федерации». - Электрон. текстовые дан. - Режим доступа: http://www. consultant.ru/document/cons_doc_LAW 208191/4dbff9722e14f63a309bce 4 c 2 ad $3 \bar{d}$ $12 \mathrm{cc} 2 \mathrm{e} 85 \mathrm{f} 10 /$. - Загл. с экрана.

Указ Президента РФ от 09.05.2017 № 203 «О Стратегии развития информационного общества Российской Федерации на 2017-2030 годы». Электрон. текстовые дан. - Режим доступа: http://www.consultant.ru/document/cons_doc_ LAW_216363/.-Загл. с экрана.

Указ Президента РФ от 13.05.2017 № 208 «О Стратегии экономической безопасности Российской Федерации на период до 2030 года». - Электрон. текстовые дан. - Режим доступа: http:// www.consultant.ru/document/cons_doc_ LAW_216629/.-Загл. с экрана.

Цифровая экономика : Глобальные тренды и практика российского бизнеса, 2017. - Электрон. текстовые дан. - Режим доступа: https://imi. hse.ru/pr2017_1._Загл. с экрана.

Цифровой потенциал стран-участниц ЕАБР, 2019. Электрон. текстовые дан. - Режим доступа: https://eabr.org/upload/iblock/551/EABR Digital_Potential_06_2019.pdf.-Загл. с экрана.

Что такое цифровая экономика? Тренды, компетенции, измерение : докл. к XX апр. Междунар. науч. конф. по проблемам развития экономики и общества, г. Москва, 9-12 апр. 2019 г. / Г. И. Абдрахманова [и др.] ; науч. ред. Л. М. Гохберг. - М. : Изд. дом Высш. шк. экономики, 2019. - 82 с. - Электрон. текстовые дан. - Режим доступа: https://www.hse.ru/data/ 2019/04/12/11780046712\%20\%D0\%A6\% D0\%B8\%D1\%84\%D1\%80\%D0\%BE\%D0\% B $2 \%$ D $0 \%$ B $0 \%$ D $1 \% 8$ F $\%$ D $1 \% 8$ D \% D $0 \%$ BA $\%$ D $0 \%$ BE $\%$ D $0 \%$ BD $\%$ D $\% \% B E \%$
D0\%BC\%D0\%B8\%D0\%BA\%D0\%B0.pdf. Загл. с экрана.

Acemoglu, D. Why Nations Faily. The Origins of Power Prosperity and Poverty / D. Acemoglu, J. A. Robinson. - N. Y. : Grown Business, 2012.

Applying Technology Convergence for Innovation in Nordic regions Nordic Innovation Centre(NICe). Oslo: Nordic Innovation Centre, 2009. - 49 p.

Grossman, G. M. Innovation and Growth in the Global Economy / G. M. Grossman, E. Helpman. Cambridge : MIT Press, 1991.

Jones, Ch. Sources of U.S. Economic Growth in a World of Ideas / Ch. Jones // The America Economic Review. - 2002. - Vol. 92, no. 1. - P. 220-239.

Next Silicon Valley: Riding the Waves of Innovation. Joint Venture Silicon Valley Network, 2001. (NSV). - Electronic text data. - Mode of access: https://jointventure.org/images/stories/pdf/ nsvridingwaves.pdf. - Title from screen.

Rodrik, D. Institutions Rule: The Primacy of Institutions over Geography and Integration in Economic Development / D. Rodrik, A. Subramanian, F. Trebbi // IMF Working Paper. - 2002. - Electronic text data. - Mode of access: https://www.imf.org/external/pubs/ft/ wp/2002/wp02189.pdf. - Title from screen.

Warwick, K. Beyond Industrial Policy. Emerging Issues and New Trends / K. Warwick // OECD Science, Technology and Industry Policy Papers. - 2013. No. 2. - Mode of access: https://www.oecd-ilibrary. org/docserver $/ 5 \mathrm{k} 4869 \mathrm{clw0xpen} . \mathrm{pdf}$ ?expires= 1610266071\&id=id\&accname= guest\&checksum= BF93484DE3B997B5475B812E055718EC. - Title from screen.

\section{REFERENCES}

Doklad o cifrovoj ekonomike. Sozdanie stoimosti $i$ poluchenie vygod: posledstviya dlya razvivayushchihsya stran [Report on the Digital Economy. Value Creation and Benefits: Implications for Developing Countries]. 2019. URL: https://unctad.org/system/files/officialdocument/der2019_overview_ru.pdf.

Inshakov O.V. Ekonomicheskaya genetika $i$ nanoekonomika [Economic Genetics and Nanoeconomics]. Volgograd, Izd-vo VolGU, $2007.94 \mathrm{p}$.

Inshakova E.I. Formirovanie ekosistemy cifrovoj ekonomiki Rossijskoj Federacii: institucional'nyj aspect [Formation of the Ecosystem of the Digital Economy of the Russian Federation: Institutional Aspect]. Vestnik Volgogradskogo gosudarstvennogo universiteta. Ekonomika [Journal of Volgograd State University. Economics], 2020, vol. 22, no. 4, 
pp. 5-17. DOI: https://doi.org/10.15688/ek.jvolsu. 2020.4.1.

Kleiner G.B. Jekonomika jekosistem: shag v budushhee [The Economy of Ecosystems: A Step into the Future]. Jekonomicheskoe vozrozhdenie Rossii [Economic Revival of Russia], 2019, no. 1 (59), pp. 40-45.

Mezhdunarodnyy valyutnyy fond [International Monetary Fund]. URL: https://www.imf.org/en/ Publications/WEO/weo-database/2020/ October; https://knoema.com.

Poslanie Prezidenta Rossijskoj Federacii Federal'nomu Sobraniyu ot 01.12.2016 [Presidential Address to the Federal Assembly of December 1, 2016]. Parlamentskaya gazeta, 2016, no. 45, December 2.

Postanovlenie Pravitel'stva RF ot 02.03.2019 no. 234 «O sisteme upravleniya realizaciej nacional’noj programmy «Cifrovaya ekonomika Rossijskoj Federacii»: (v red. ot 21.08.2020) [Decree of the Government of the Russian Federation of March 2, 2019 No. 234 "On the Management System for the Implementation of the National Program Digital Economy of the Russian Federation" (As Amended on August 21, 2020)]. URL: http://www.consultant.ru/document/cons doc LAW 319701/.

Aganbegyan A.G., Klepach A.N., Porfir'ev B.N., Uzyakov M.N., Shirov A.A. Postpandemicheskoe vosstanovlenie Rossijskoj ekonomiki i perekhod $\mathrm{k}$ ustojchivomu social'no-ekonomicheskomu razvitiyu [Post-Pandemic Recovery of the Russian Economy and the Transition to Sustainable Socio-Economic Development]. Problemy prognozirovaniya [Forecasting Problems], 2020, no. 6, pp. 18-26.

Abdrahmanova G.I., Baskakova O.E., Vishnevskij K.O., Gohberg L.M. et al. Tendencii razvitiya interneta $v$ Rossii $i$ zarubezhnyh stranah: analiticheskij doklad [Internet Development Trends in Russia and Foreign Countries: Analytical Report]. Moscow, NIU VShE, 2020. 144 p. URL: https://issek.hse.ru/mirror/pubs/ share/345060549.pdf.

Ukaz Prezidenta RF ot 05.12.2016 № 646 «Ob utverzhdenii Doktriny informacionnoj bezopasnosti Rossijskoj Federacii» [Decree of the President of the Russian Federation of December 5, 2016 No. 646 "On the Approval of the Doctrine of Information Security of the Russian Federation"]. URL: http://www. consultant.ru/document/cons_doc_LAW 208191/4dbff9722e14f63a309bce4c 2 ad3 $\overline{\mathrm{d}}$ $12 \mathrm{cc} 2 \mathrm{e} 85 \mathrm{f} 10 /$.

Ukaz Prezidenta RF ot 09.05.2017№ 203 «O Strategii razvitiya informacionnogo obshchestva Rossijskoj Federacii na 2017-2030 gody»
[Decree of the President of the Russian Federation of May 9, 2017 No. 203 "On the Strategy for the Development of the Information Society of the Russian Federation for 20172030"]. URL: http://www.consultant.ru/ document/cons_doc_LAW_216363/.

Ukaz Prezidenta RF ot 13.05.2017№ 208 «O Strategii ekonomicheskoj bezopasnosti Rossijskoj Federacii na period do 2030 goda» [Decree of the President of the Russian Federation of May 13, 2017 No. 208 "On the Strategy of Economic Security of the Russian Federation for the Period Until 2030"]. URL: http://www.consultant.ru/ document/cons_doc_LAW_216629/.

Cifrovaya ekonomika: Global'nye trendy i praktika rossijskogo biznesa [Digital Economy: Global Trends and Practice of Russian Business]. 2017. URL: https://imi.hse.ru/pr2017_1.

Cifrovoj potencial stran-uchastnic EABR [The Digital Potential of the EDB Member Countries]. 2019. URL: https://eabr.org/upload/iblock/551/ EABR_Digital_Potential_06_2019.pdf.

Abdrahmanova G.I., Vishnevskij K.O., Gohberg L.M. et al. Chto takoe cifrovaya ekonomika? Trendy, kompetencii, izmerenie: dokl. k XX apr. Mezhdunar. nauch. konf. po problemam razvitiya ekonomiki i obshchestva, g. Moskva, 9-12 apr. 2019 [What Is the Digital Economy? Trends, Competencies, Measurement. Report to the $20^{\text {th }}$ April International Academic Conference on Economic and Social Development, Moscow, April 9-12, 2019]. Moscow, Izdatelskiy dom Vysshey shkoly ekonomiki, 2019. 82 p. URL: https://www.hse.ru/data/2019/04/12/ $11780046712 \% 20 \% \mathrm{D} 0 \% \mathrm{~A} 6 \% \mathrm{D} 0 \% \mathrm{~B} 8 \% \mathrm{D} 1 \%$ $84 \% \mathrm{D} 1 \% 80 \% \mathrm{D} 0 \% \mathrm{BE} \% \mathrm{D} 0 \% \mathrm{~B} 2 \% \mathrm{D} 0 \% \mathrm{~B} 0 \%$ D1\%8F \%D1\%8D\%D0\%BA\%D0\%BE\%D0\% BD \%D0\%BE\%D0\%BC\%D0\%B8\%D0\% $\mathrm{BA} \% \mathrm{D} 0 \% \mathrm{~B} 0 . \mathrm{pdf}$.

Acemoglu D., Robinson J.A. Why Nations Faily. The Origins of Power Prosperity and Poverty. New York, Grown Business, 2012.

Applying Technology Convergence for Innovation in Nordic Regions. Nordic Innovation Centre (NICe). Oslo, Nordic Innovation Centre, 2009. 49 p.

Grossman G.M., Helpman E. Innovation and Growth in the Global Economy. Cambridge, MIT Press, 1991.

Jones Ch. Sources of U.S. Economic Growth in a World of Ideas. The America Economic Review, 2002, vol 92, no. 1, pp. 220-239.

Next Silicon Valley: Riding the Waves of Innovation. Joint Venture Silicon Valley Network, 2001 (NSV). URL: https://jointventure.org/images/ stories/pdf/nsvridingwaves.pdf.

Rodrik D., Subramanian A., Trebbi F. Institutions Rule: The Primacy of Institutions over Geography and 
E.A. Петрова, E.А. Фокина. Государственная политика в области конвергентных технологий

Integration in Economic Development. IMF Working Paper, 2002. URL: https://www.imf.org/ external/pubs/ft/wp/2002/wp02189.pdf.

Warwick K. Beyond Industrial Policy. Emerging Issues and New Trends. OECD Science, Technology and Industry Policy Papers, 2013, no. 2. URL: https://www.oecd-ilibrary.org/docserver/ 5k4869clw0xp-en.pdf?expires $=1610266071 \&$ id=id\&accname $=$ guest\&checksum $=$ BF93484DE 3B997B5475B812E055718EC.

\section{Information About the Authors}

Elena A. Petrova, Doctor of Sciences (Economics), Professor, Head of the Department of Applied Informatics and Mathematical Methods in Economics, Volgograd State University, Prosp. Universitetsky, 100, 400062 Volgograd, Russian Federation, ea_petrova@mail.ru, https://orcid.org/0000-0002-6417-9498

Elena A. Fokina, Candidate of Sciences (Economics), Associate Professor, Department of Applied Informatics and Mathematical Methods in Economics, Volgograd State University, Prosp. Universitetsky, 100, 400062 Volgograd, Russian Federation, fokina-ea@volsu.ru, https://orcid.org/0000-0003-3996-9161

\section{Информация об авторах}

Елена Александровна Петрова, доктор экономических наук, профессор, заведующая кафедрой прикладной информатики и математических методов в экономике, Волгоградский государственный университет, просп. Университетский, 100, 400062 г. Волгоград, Российская Федерация, ea_petrova@mail.ru,https://orcid.org/0000-0002-6417-9498

Елена Анатольевна Фокина, кандидат экономических наук, доцент кафедры прикладной информатики и математических методов в экономике, Волгоградский государственный университет, просп. Университетский, 100, 400062 г. Волгоград, Российская Федерация, fokina-ea@volsu.ru, https://orcid.org/0000-0003-3996-9161 